\title{
Why do Visitors intend to use Indoor Navigation and Indoor Localization Systems in Hospitals? A Quantitative Survey from Germany
}

\author{
Johannes Wichmann \\ Wismar University of Applied Sciences \\ University of Rostock \\ johannes.wichmann@hs-wismar.de
}

\author{
Michael Leyer \\ University of Rostock \\ Queensland University of Technology \\ michael.leyer@uni-rostock.de
}

\begin{abstract}
Hygiene is a very important topic in hospitals. Indoor Navigation/Indoor Localization (IN/IL) approaches are an effective way to minimize unplanned interactions and thus infections in hospitals. As hospitals are a relatively new area for the implementation of IN/IL systems, this research contributes to the field as it investigates the reasons for its acceptance by hospital visitors as an important target group. We surveyed 323 visitors in Germany concerning their reasons and intention to use an IN/IL system in a hospital. The results show that intention to use is quite high with attitude being the main predictor, perceived norms having some influence and behavioral control not being relevant at all. Thus, we highlight that the reasoned action approach is suitable for the analysis and crystallize the relevant factors influencing usage intention. The results contribute to our understanding how to convince visitors in hospitals to use IN/IL systems.
\end{abstract}

\section{Introduction}

In 2020, hygiene is still a relevant topic in German hospitals as hospital related infections lead to more deaths than the road traffic in Germany [33]. As social distancing is known to prevent infections [30] and the navigation in hospitals is often analogue (e.g. by painted lines on the wall and floor [3]), this aggravates the possibilities to keep distance to other individuals since everyone will use the same lines. Here, Indoor Navigation/Indoor Localization (IN/IL) systems could contribute to social distancing, as every individual would receive their own navigational route depending on the target, e.g. by using the Bluetooth-Signal as well as the acceleration of a smartphone [24]. Furthermore, such IN/IL systems for hospitals show first results in reducing infections. Approaches concerning hand hygiene [24] and patient localization [25] could improve the hygiene in hospitals, e.g. for a better preparation regarding pandemic crises or concerning the emergency care management [28]. By now, IN/IL systems are relatively new inventions for hospitals [27] due to technological development. The devices, e.g. Bluetooth Beacons or RFID tags, become cheaper, which in turn, makes the implementation more attractive [8]. Combined with the market penetration of smartphones that could be used for IN/IL systems ("bring your own device" (BYOD)) concerning the German households with 98\% [11], the BYOD approach would reduce costs for the implementation of an IN/IL system regarding the hospital. Additionally, the BYOD approach could facilitate the usage of such a system, since it is likely that the handling of the own device will be easier than using a foreign one. Moreover, first implementations of IN/IL systems in e.g. German [36] or US [37] hospitals using smartphones show the demand for such systems.

There is however not much research concerning navigational requirements of the users of an IN/IL system in a hospital. Nonetheless, research concerning users' navigational needs in more general terms, e.g. by investigating the usability of location based solutions in commercial contexts by surveying frequent IN/IL system users, exists [5]. The only study available in the hospital context was conducted for hospital staff, showing that there is a demand for an IN/IL system in the Geneva University Hospital [3]. However, patients (or visitors) reasons for using IN/IL systems in hospitals have not yet been investigated despite an urgent need to navigate these groups that are unfamiliar with the environment. Therefore, we aim to close this gap and pose the research question: Which factors determine the intention of visitors (patients and their relatives) to use an IN/IL system in a hospital? Our analysis is based on the reasoned action approach (RAA) representing a causal model which proposes that the behavior in terms of using is determined by behavioral (BB), normative (NB) and control beliefs (CB) [15]. Using quantitative data from 323 visitors of German hospitals, we set up a 
structural equation model showing which factors are relevant for the intention (I) to use. Theoretically, our results show the applicability of the RAA to the domain and second, we determine the significant factors influencing the intention to use IN/IL systems. Hence, our results contribute to our understanding why patients have the intention to use IN/IL systems. Hospitals can use these insights to ensure usage when investing in such a system to increase hygiene in hospitals. This would not only help with general issues like multiresistant germs, but also to allow more visitors in hospitals in the current ongoing pandemic situation.

Section 2 contains the theoretical background of the research and introduces the deducted hypotheses. Section 3 provides materials and method. Section 4 presents the results that are discussed in section 5 . Finally, section 6 concludes the research and provides an outlook for further investigations.

\section{Theoretical background}

\subsection{Indoor Navigation/Indoor Localization}

To implement IN/IL in a specific environment, localization systems are used. Those systems are dedicated to estimate or find a specific position of an individual or object [10]. Basically, these systems are based on a process that determines the position of a particular mobile client by a set of reference positions within a predefined area [12]. To perform this process, different localization techniques, e.g. Wi-Fi or Bluetooth Low Energy combined with a calculation principle for the estimation of the position, e.g. trilateration, are necessary [24]. Then, this combination can be used to fulfill requirements in a hospital, such as to prevent newborn-kidnapping [29] or to track patients' physical activities in rehabilitation [32].

\subsection{Reasoned Action Approach}

To explain intention to use an indoor navigation and localization system, a psychological perspective is considered with RAA as the underlying theory. The RAA is descended from the widely accepted Theory of Reasoned Action [1, 2, 13, 14] in psychological studies [4] dedicated to explain individual behavior. According to RAA, the individual behavior is rooted in behavioral intentions that are influenced by (1) an opinion an individual has regarding the behavior that represents the individual's attitude (Att) towards the behavior; (2) the influence of other individuals as perceived norms (PN); and (3) the possibility that the individual may influence the behavior called perceived behavioral control (PBC) [15].
The positive or negative feelings of an individual about performing the target behavior is referred by attitude towards the behavior. It is determined by assessing the individual's beliefs concerning the attributes and characteristics associated with the behavior (or the inherent objective, respectively). The individual consequences of the behavior as well as the desirability assessments of those consequences influence the overall attitude. Perceived norms handle the individual's perception of whether other people (that are most important to her/him) think that she/he should perform the behavior in question. Those norms are based on normative beliefs that refer to relevant individuals or groups who support or oppose a given behavior. The sum of the perception and motivation assessments for all relevant referents are expressed as perceived norms $[2,13,14]$. The question of whether she/he is capable of, or has control over, performing the behavior in question is answered by the perceived behavioral control. It is based on the control beliefs that refer to situational or personal factors, which the individual deems important regarding the behavior. The intention to perform a behavior is dependent concerning the attitude towards a certain behavior, the perceived norms, and the perceived behavioral control. The more positive those aspects are, the more likely is that the individual will have the intention to perform the behavior.

Conclusively, performing a certain behavior entails a process of comparing and selecting among attitudes, perceived norms and perceived behavioral controls associated with each of the alternative behaviors in the choice set [35].

\subsection{Hypotheses and research model}

As RAA has to be adapted to a specific context [15], we transfer the approach to the context of using IN/IL systems in hospitals. It serves as a theoretical model that enables to explain the predictive validity for the application of an IN/IL system in a hospital.

First, to determine an individual's value perception of using an IN/IL system, behavioral beliefs must be considered. This includes a determination of whether an IN/IL system is helpful for the individual in terms of finding the right location or not. Furthermore, the hygiene during movements through the hospitals is investigated, since this could be improved by the system and could lead to a lower risk regarding infections in hospitals [24] (e.g. during a pandemic crisis).

These beliefs influence an individual's attitude in terms of positive or negative feelings towards an IN/IL system in a hospital. In our case, positive feelings refer to whether the individual feels that an IN/IL system is beneficial, satisfactorily, important, and pleasant. 
Furthermore, it is investigated whether the individual likes the IN/IL system. These are important aspects in RAA according to [19]. An individual that has a positive attitude is then expected to have a higher intention to use an IN/IL system in a hospital $[15,35]$. This leads to the first set of hypotheses:

H1: The better the behavioral beliefs concerning the use of an IN/IL system in a hospital are, the more positive is the attitude of an individual regarding the system.

$\mathrm{H} 2$ : The more positive the attitude of an individual concerning the use of an IN/IL system in a hospital is, the higher is the intention to use such a system.

Second, the normative beliefs are considered as they capture the opinion of other relevant individuals. Relevant people in our investigation are the family and friends of the individual [15]. Those normative beliefs then lead to perceived pressure or motivation to use an IN/IL system in a hospital (subjective norms). This reflects whether an individual thinks that these reference persons support or urge the usage of an IN/IL system. The normative influence regarding the IN/IL system in a hospital is based on hospital visitors seeking exchange with others with the aim of gaining experience from other IN/IL systems and opinions, since the use of an IN/IL system could be very complex and energy consuming concerning the individual's device for navigation [38]. According to the RAA, the more positively this support is perceived in relation to the norms, the higher is the intention to use an IN/IL system in a hospital. This leads to a second set of hypotheses:

H3: The higher the normative beliefs concerning the use of an IN/IL system in a hospital are, the more positive are the perceived norms of an individual regarding the system.

H4: The more positive the perceived norms of an individual regarding the use of an IN/IL system in a hospital are, the higher is the intention to use this system.

Third, control beliefs impede or facilitate the likelihood of an individual using an IN/IL system in a hospital. In this regard, such factors are the easiness concerning the access to an IN/IL system as well as the necessity of an explanation concerning the use of the system as the complexity and communication concerning such systems are deemed as two of the most critical success factors concerning IT projects in hospitals [34]. If one is able to use the system is dependent on those success factors. The control beliefs then lead to the perceived behavioral control that reflects whether an individual perceives that she/he has the new system under control. This is the case, if the individual is able to access the system easily and to use it under guidance [9]. Conclusively, the intention is positively influenced by a higher perceived behavioral control $[15,35]$. This leads to a third set of hypotheses:

H5: The higher the control beliefs concerning an IN/IL system in a hospital are, the more positive is the perceived behavioral control of an individual regarding the system.

H6: The more positive the perceived behavioral control in terms of an IN/IL system in a hospital is, the higher is the intention to use the system.

Finally, our analysis focuses on the connection between spatial abilities (SA) and the perceived behavioral control as well as spatial abilities and the intention to use an IN/IL system in a hospital. The assumption is that individuals, which are good at navigating through buildings using the shortest path without any assistance are confident about a potential use of such an IN/IL system in a hospital concerning the perceived behavioral control. In addition, people that are good at navigating themselves are not in an urgent need to use an IN/IL system [31] and can therefore decide whether or not they want to use the system, which would lead to a higher perceived behavioral control and a lower intention to use. Therefore, the hypotheses are:

\section{H7: The higher the spatial abilities are, the higher is the perceived behavioral control.}

H8: The higher the spatial abilities are, the lower is the intention to use an IN/IL system in a hospital.

Conclusively, fig. 1 represents the research model and the respective hypotheses in line with RAA.

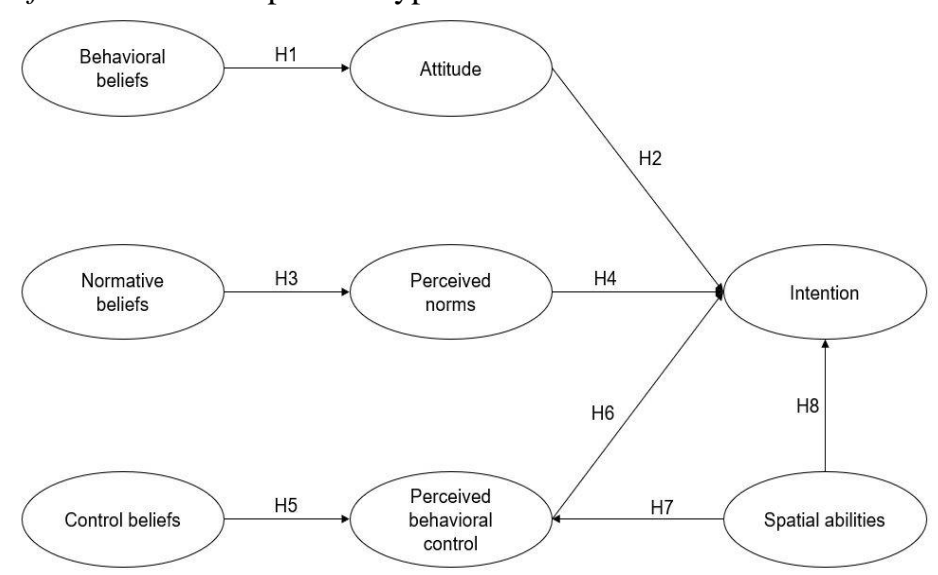

Figure 1: research model 


\section{Material and method}

\subsection{Measures}

All measures within the model use a seven-point Likert scale for each item (from "do not agree at all" (represented by the number " 1 ") to "completely agree" (rep. by no. "7")) [15]. The contextual adjustments of the questionnaire were guided closely by the original framework following Fishbein and Ajzen in that "it is important to realize that there is no single reasonedaction questionnaire. Each investigation requires construction of a suitable questionnaire" [15]. We therefore incorporated the aforementioned dimensions relevant for hypothesis development as items for the context of IN/IL systems in hospitals. Furthermore, at the beginning of the questionnaire we clarified what an IN/IL system is to allow adequate assessment of participants: "An IN/IL system is an ultrasound-based, application-supported navigation and location solution in the hospital. The application should locate devices as effectively as possible and navigate people and avoid contact points in order to facilitate compliance with hygiene measures (e.g. keeping people at a distance)."

\subsection{Participants and data collection}

To gather visitors of hospitals, the crowd working platform Clickworker (similar to Amazon MTurk) was used. On this platform, our survey emerged as a task that was solvable by anyone who (a) lives in Germany (b) is able to answer the survey since it was conducted in German, (c) visited a hospital at least once during the last 365 days and (d) was at least 18 years old. Beside those restrictions, we had no further influence concerning the composition of our participant group. As the 323 participants were paid for participating in a survey by the unsupervised online platform Clickworker and could have aimed for a fast-solving of the questionnaire without actually reading it, we followed the recommendations of Goodman et al. [17] (also revealing that such data is similar to voluntary participants) by using a short survey that we enriched with attention check questions. The youngest participant was 18 years old, the oldest 68 years young. The age's mean was 36.08 years, with a variance of 137.48 years and a standard derivation of 11.73 years. $77.4 \%$ of the participants were between 18 and 44 years old, $22.29 \%$ were in the range of age between 45 and 64 years.

\subsection{Validity and reliability assessment}

To test the proposed model, a partial least square (PLS) approach for structural equation modelling
(SEM) is used. If the research object is to explain and predict the target construction in structural models, or to identify key drivers, the PLS method is particularly adequate, compared to covariance-based SEM [18]. Variance-based SEM develops parameters that "maximize the explained variance of the dependent constructs" [18], like multiple regressions analysis. We used SmartPLS 3.2.9 to determine our results. Thereby, our weightings were estimated with a path method and the path coefficients' significance was determined by using a bootstrapping procedure with 5,000 samples [18].

We follow the requirements of Hair et al. [18] and Hulland [23] to test (1) internal consistency reliability, (2) indicator reliability, (3) convergent validity and (4) discriminant validity. First, internal consistency was confirmed for each variable (see Appendix A-6). Second, the reliability of indicators of the reflective variables "attitude", "perceived norms", and "perceived behavioral control" is fulfilled [18] (see Appendix A-2). Third, the convergent validity regarding the reflective variables is confirmed (see Appendix A-6). Fourth, we analyzed the discriminant validity using heterotraitmonotrait (HTMT, see Appendix A-7) [21]. Since all the requirements were met, adequate reliability and validity of the reflective measure properties can be concluded.

Regarding the formative variables, the variance inflation factor values check multicollinearity among the indicators and are in line with the requirements (see Appendix A-4). Further, the relative and absolute importance of indicators were tested with loadings and weights that were all significant (see Appendix A-4). By checking whether the bivariate correlations are higher between an indicator and the variable than between the indicators [7], it is possible to test the heterogeneity between the indicators. Thereby, the results represent that there are no suppressors and/or no collinear indicators that can be identified (see Appendix A-5).

To determine the quality of our structural model, we conducted several tests. For this, the standardized root mean square residual (SRMR) as a measure of the approximate fit of our composite factor as well as common factor model was used [20]. Concerning our model, we reached .075 for the SRMR composite factor model and .10 for the SRMR common factor model. Additionally, according to [26] a blindfolding procedure involving an omission distance of 7 is used, assessing the prediction relevance of the model [22]. Furthermore, the test determined positive Stone-Geisser Q2 values (see Appendix A-8). Thereby, a strong overall predictive power can be concluded for the model [22]. 


\section{Results}

The descriptives as well as the correlations concerning the variables of our research model enable some high correlations to be identified (see Appendix A-5). This is likely to occur despite the components being conceptually different [15]. The quality of the research model is not affected according to the criteria tested, as demonstrated especially with HTMT in section 3. The results of our analysis concerning the research model are presented in fig. 2 .

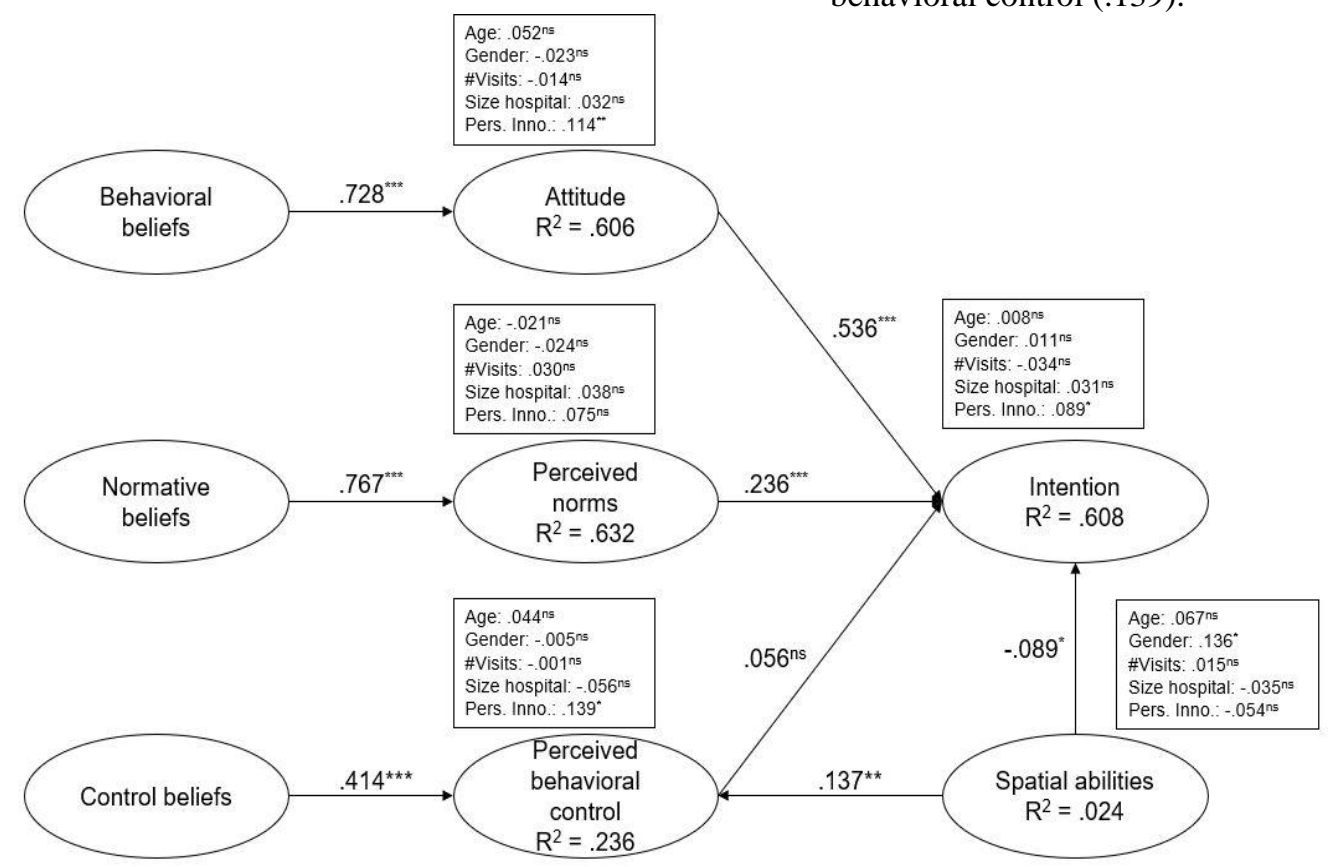

Figure 2: Research model results (Notes: * $\mathrm{p}<.05 ; * * \mathrm{p}$ $<.01 ; * * * \mathrm{p}<.001$; one-tailed tests)

We determined strong empirical evidence for $\mathrm{H} 1$ $\left(ß=.728 * * * ; \mathrm{f}^{2}=1.153\right), \mathrm{H} 3 \quad\left(\beta=.767 * * * ; \mathrm{f}^{2}=1.389\right)$ as well as H5 $\left(\beta=.414^{* * * ;} \mathrm{f}^{2}=0.179\right)$ showing that the beliefs are relevant antecedents supporting the hypotheses. According to the $\mathrm{R}^{2}$, an increase in behavioral beliefs lead to a higher positive attitude whereas $60.6 \%$ of the attitudes' variance can be explained by the behavioral beliefs. Furthermore, the normative beliefs have a strong influence on perceived norms $(63.2 \%)$. The influence of the control beliefs towards the perceived behavioral control is lower than the two aforementioned beliefs and the percentage of explained variance is comparatively low (23.6\%).

By investigating $\mathrm{H} 2 \quad\left(\beta=.536 * * * ; \quad \mathrm{f}^{2}=.381\right), \quad \mathrm{H} 4$ $\left(\beta=.236 * * * ; \mathrm{f}^{2}=.087\right)$ and H8 $\left(\beta=-.089 * ; \mathrm{f}^{2}=.019\right)$ we determined that $\mathrm{H} 2$ and $\mathrm{H} 4$ are supported while $\mathrm{H} 8$ is not. Thereby, especially the attitude has a strong influence towards the intention to use an IN/IL system in a hospital. Concerning the $\mathrm{H} 8$ it is conspicuous that the spatial abilities have a negative influence towards the intention to use. As we investigated H6 $\left(\beta=.056^{\text {ns; }}\right.$ $\left.\mathrm{f}^{2}=.006\right)$ and $\mathrm{H} 7\left(\beta=.137 * * * ; \mathrm{f}^{2}=.023\right)$ we determined that perceived behavioral control is not a predictor for the intention to use and thereby H6 is not supported, whereas spatial abilities are a predictor for perceived behavioral control and $\mathrm{H} 7$ is supported. Additionally, we have some control variables for the research model. All of them are not significant except for personal innovativeness on attitude (.114) and on perceived behavioral control (.139).

\section{Discussion}

The results show that attitude as well as perceived norms are strong predictors for the intention to use an IN/IL system in a hospital. As attitude driven by behavioral beliefs is often seen as the major predictor for the intention to use [15], this can be confirmed by our investigation.

Concerning perceived norms, theorists of rational choices argue that our behavior as humans is usually guided by self-interest and we therefore accept social norms as limits on such behaviors. Derived from that, the main attribute of social norms is to ensure that they do not serve only an individual's interest as they represent a larger social system [6]. Regarding our research, those perceived norms have a significant influence towards the intention to use the system. As the perceived norms reflect interests of a larger social system, our analysis concluded that the participants tend to use the system if it is recommended by parties that are important for them, in our case family and friends.

As perceived behavioral control is not significant in terms of predicting the intention to use the system, we are not able to derive statements regarding the individuals' actual control about the decision to use the IN/IL system. Additionally, it is likely that most of those surveyed have not used an indoor navigation system. This may be related to market penetration of IN/IL systems that is described by the statement: "By 2020, 
$65 \%$ of enterprises will require indoor location asset tracking (both people and equipment) to be part of all access layer infrastructure communication decisions (up from less than 10\% today)" [39]. Therefore, the demand for IN/IL systems is rapidly rising, but the usage of IN/IL systems in several environments (e.g. healthcare, retail, manufacturing etc.) today is limited [27]. As social distancing efforts are increasing during current pandemic situations [16], the demand for IN/IL systems might be even higher in several environments than the $65 \%$ predicted. As we often lack sufficient information about all the relevant internal and external factors that influence the perceived behavioral control of an individual, such research results are a typical appearance [15].

Concerning the spatial abilities, the mean value of 4.26 shows that participants do not have high but rather average abilities for indoor navigation. Hence, a need can be seen to install such systems which is also reflected in the mean intention of 5.34.

\section{Conclusion}

Our study is motivated by analyzing how relevant the implementation of an IN/IL system for a hospital is, by considering the visitors' perspective. The results show that the attitude towards IN/IL systems as well as social norms of relevant reference groups (best friends and family) have a positive impact regarding the intention to use the system. Our findings contribute to the understanding of a potential use of a respective system by investigating the important target group of hospital visitors as it contains, among others (e.g. relatives of patients), the target group of hospital patients.

First, our results show that the RAA is an adequate approach to analyze the intention to use IN/IL systems in hospitals. The explained variance indicates that intention is predicted well and that relevant aspects in the context are covered.

Second, our results show that, concerning the intention to use an IN/IL system in a hospital, the participants' attitude regarding the system is relevant as they tend to use the system, if their attitude towards it is positive. Third, social norms are important for the intention to use the system, as the participants tend to use it, if it would be recommended by the family or friends. As spatial abilities and personal innovativeness are also significant concerning the intention to use the respective system, they also have to be considered, while implementing an IN/IL system in a hospital. Our findings determined that potential users of the system (a) have a positive attitude towards the system and are therefore intended to use it and/or (b) have friends or family members, who recommend the system and are thereby responsible for the intention to use the system concerning the participant. Consequently, the control variables limit the target group of the potential users, as the intention to use the system is lower for those participants who are not personal innovative in terms of new technologies. Low characteristics in terms of personal innovativeness reflects people, who (a) are reluctant concerning experimenting and the use of new technologies and/or (b) are not the first ones in their respective influence group (family and friends) to try out new technologies (see Appendix A-1).

Concerning practical implications, we recommend hospitals to implement IN/IL systems especially given the experience with the current pandemic. Since we determined strong evidence that attitude is the most important variable, rational explanations using examples of the current pandemic could be helpful to convince potential users but also to let them demand such systems. Additionally, people tend towards an intention, if it is positively related to social norms within their environment [15]. As we determined a strong evidence that recommendations by influence groups (family and friends) are positively related to the intention to use the system, it is likely that the number of users increases. Potential users could be attracted by highlighting that such a system keeps their friends and families safe and/or that there could be more opportunities to visit relatives in hospitals in the current pandemic situation when such systems would reduce virus spreads. Hospitals benefit from this research by gaining valuable and reliable data concerning the implementation of an IN/IL system in a hospital. We defined that people intend to use the system who (a) have a positive attitude towards it and/or (b) get the system recommended by influence groups as well as (c) are personally innovative enough to try out/experiment with new technologies. As in 2020, $98 \%$ of the German households have at least one smartphone [11]. By considering that the possession and frequent use of a smartphone is a very important entry barrier to use an IN/IL system in a hospital, the coverage rate of German households combined with the findings of our research represent a large, potential group of users of an IN/IL system in a hospital. Furthermore, an IN/IL system is relevant for every hospital in Germany, since our findings conclude that the size of the hospital is not significant concerning the intention to use such a system.

Our research is however subject to limitations as any research. First, the hospital visitors had to imagine the use of a non-specified IN/IL system in a hospital that is not related to any existing approaches. The results may differ from RAA surveys concerning specific IN/IL systems. Second, as we used the crowdworker platform Clickworker to gather our participants (section 3.2.), participants are digitally engaged, since they used an 
online platform to answer the survey. Therefore, an analogue survey (e.g. pen and paper) within a hospital could lead to different individuals involved and thus different results. Third, we only targeted visitors while there are other stakeholders (service contractors, employees). For further research, additional studies concerning the hospital's staff members investigating their intention to use an IN/IL system in a hospital would be interesting. The results of such an investigation combined with the outcome of this research would further contribute to the knowledgebase of IN/IL research in hospitals. Thereby, a hospital could derive demands for an IN/IL system in their respective hospital. Fourth, we did not consider other settings in which an IN/IL system would be relevant (e.g. hardware store) and interact with the hospital context. Further investigations regarding the general acceptance and/or in combination with other contexts, e.g. how likely is the usage of an IN/IL system in a hardware store after the system was used in a hospital by the participant, would be interesting.

\section{References}

[1] Ajzen, I. and N.G. Cote, "Attitudes and the prediction of behavior", in Attitudes and attitude change, R. Prislin and W.D. Crano, Editors. 2008. Psychology Press: New York, London.

[2] Ajzen, I. and M. Fishbein, "Attitudinal and normative variables as predictors of specific behavior", Journal of Personality and Social Psychology, 27(1), 1973, pp. 4157.

[3] Anagnostopoulos, G.G., M. Deriaz, J.-M. Gaspoz, D. Konstantas, and I. Guessous, "Navigational needs and requirements of hospital staff: Geneva University hospitals case study", in 2017 International Conference on Indoor Positioning and Indoor Navigation (IPIN): 1821 September, 2017, Sapporo, Japan, 2017 International Conference on Indoor Positioning and Indoor Navigation (IPIN), Sapporo, 9/18/2017 - 9/21/2017. 2017. IEEE: Piscataway, NJ.

[4] Armitage, C.J. and M. Conner, "Efficacy of the Theory of Planned Behaviour: a meta-analytic review", The British journal of social psychology, 40(Pt 4), 2001, pp. 471499.

[5] Basiri, A., E.S. Lohan, T. Moore, A. Winstanley, P. Peltola, C. Hill, P. Amirian, and P. Figueiredo e Silva, "Indoor location based services challenges, requirements and usability of current solutions", Computer Science Review, 24, 2017, pp. 1-12.

[6] Boudon, R., "Beyond Rational Choice Theory", Annual Review of Sociology, 29(1), 2003, pp. 1-21.

[7] Cenfetelli, R.T. and G. Basselier, "Interpretation of Formative Measurement in Information Systems Research", Management Information Systems Quarterly, 33(4), 2009, pp. 689-708.
[8] Chen, C.-Y., C.-W. Hsieh, Y.-H. Liao, and T.-J. Yin, "Implementation of Wearable Devices and Indoor Positioning System for a Smart Hospital Environment", in 2018 International Symposium in Sensing and Instrumentation in IoT Era (ISSI): 6-7 Sept. 2018, 2018 International Symposium in Sensing and Instrumentation in IoT Era (ISSI), Shanghai, 9/6/2018 9/7/2018. 2018. IEEE: Piscataway, NJ.

[9] Choi, W., M.J. Rho, J. Park, K.-J. Kim, Y.D. Kwon, and I.Y. Choi, "Information system success model for customer relationship management system in health promotion centers", Healthcare informatics research, 19(2), 2013, pp. 110-120.

[10] Chriki, A., H. Touati, and H. Snoussi, "SVM-based indoor localization in Wireless Sensor Networks", in IWCMC 2017: The 13th International Wireless Communications \& Mobile Computing Conference, 2017 13th International Wireless Communications and Mobile Computing Conference (IWCMC), Valencia, Spain, 6/26/2017 - 6/30/2017. 2017. IEEE: Piscataway, NJ.

[11] German Federal Statistical Office, "Income Consumption Living Conditions", https://www.destatis.de/EN/Themes/SocietyEnvironment/Income-Consumption-LivingConditions/Equipment-Consumer-Durables/_node.html, accessed 10-1-2020.

[12] Farid, Z., R. Nordin, and M. Ismail, "Recent Advances in Wireless Indoor Localization Techniques and System", Journal of Computer Networks and Communications, 2013, 2013, pp. 1-12.

[13] Fishbein, M., "Attitude and the prediction of behavior", in Readings in attitude theory and measurement, $\mathrm{M}$. Fishbein, Editor. 1967. Wiley: New York.

[14] Fishbein, M. and I. Ajzen, Belief, attitude, intention and behavior: An introduction to theory and research, Addison-Wesley, Reading, Mass., 1975.

[15] Fishbein, M. and I. Ajzen, Predicting and changing behavior: The reasoned action approach, Psychology Press, New York, NY, Hove, 2010.

[16] Glogowsky, U., E. Hansen, and S. Schächtele, "How Effective are Social Distancing Policies? Evidence on the Fight Against COVID-19 from Germany", SSRN Electronic Journal, 2020.

[17] Goodman, J.K., C.E. Cryder, and A. Cheema, "Data Collection in a Flat World: The Strengths and Weaknesses of Mechanical Turk Samples", Journal of Behavioral Decision Making, 26(3), 2013, pp. 213-224.

[18] Hair, J.F., C.M. Ringle, and M. Sarstedt, "PLS-SEM: Indeed a Silver Bullet", Journal of Marketing Theory and Practice, 19(2), 2011, pp. 139-152.

[19] Han, S.H., K.J. Kim, M.H. Yun, S.W. Hong, and J. Kim, "Identifying mobile phone design features critical to user satisfaction", Human Factors and Ergonomics in Manufacturing, 14(1), 2004, pp. 15-29. 
[20] Henseler, J., T.K. Dijkstra, M. Sarstedt, C.M. Ringle, A. Diamantopoulos, D.W. Straub, D.J. Ketchen, J.F. Hair, G.T.M. Hult, and R.J. Calantone, "Common Beliefs and Reality About PLS", Organizational Research Methods, 17(2), 2014, pp. 182-209.

[21] Henseler, J., C.M. Ringle, and M. Sarstedt, "A new criterion for assessing discriminant validity in variancebased structural equation modeling", Journal of the Academy of Marketing Science, 43(1), 2015, pp. 115135.

[22] Henseler, J., C.M. Ringle, and R.R. Sinkovics, "The use of partial least squares path modeling in international marketing", in New challenges to international marketing, R.R. Sinkovics and P.N. Ghauri, Editors. 2009. Emerald/JAI: Bingley.

[23] Hulland, J., "Use of partial least squares (PLS) in strategic management research: a review of four recent studies", Strategic Management Journal, 20(2), 1999, pp. 195-204.

[24] Karimpour, N., B. Karaduman, A. Ural, M. Challenger, and O. Dagdeviren, "IoT based Hand Hygiene Compliance Monitoring", in 2019 International Symposium on Networks, Computers and Communications (ISNCC), 2019 International Symposium on Networks, Computers and Communications (ISNCC), Istanbul, Turkey, 6/18/2019 - 6/20/2019. IEEE.

[25] Konecny, J., M. Prauzek, R. Martinek, L. Michalek, and M. Tomis, "Real-time Patient Localization in Urgent Care: System Design and Hardware Perspective", in 2018 IEEE 20th International Conference on e-Health Networking, Applications and Services (Healthcom): 17-20 Sept. 2018, 2018 IEEE 20th International Conference on e-Health Networking, Applications and Services (Healthcom), Ostrava, 9/17/2018 - 9/20/2018. 2018. IEEE: Piscataway, NJ.

[26] Kortmann, S., "The Mediating Role of Strategic Orientations on the Relationship between Ambidexterity-Oriented Decisions and Innovative Ambidexterity", Journal of Product Innovation Management, 32(5), 2015, pp. 666-684.

[27] Lanjudkar, P., Market Research Report: Indoor Positioning and Indoor Navigation (IPIN) Market, 2020.

[28] Lee, S.-w., S.-y. Cheng, J.Y.-j. Hsu, P. Huang, and C.w. You, "Emergency Care Management with LocationAware Services", in Pervasive Health Conference and Workshops, 2006: Nov. 29, 2006 - Dec. 1, 2006, Innsbruck, Austria, 2006 Pervasive Health Conference and Workshops, Innsbruck, Austria, 11/29/2006 12/1/2006. 2006. IEEE Operations Center: Piscataway, NJ.

[29] Li, Z., Y. Yang, and K. Pahlavan, "Using iBeacon for newborns localization in hospitals", in 2016 10th International Symposium on Medical Information and Communication Technology (ISMICT): Worcester, Massachusetts, USA, March 20-23, 2016, 2016 10th
International Symposium on Medical Information and Communication Technology (ISMICT), Worcester, MA USA, 3/20/2016 - 3/23/2016. 2016. IEEE: Piscataway, NJ.

[30] Munnoli, P.M., S. Nabapure, and G. Yeshavanth, "PostCOVID-19 precautions based on lessons learned from past pandemics: a review", Zeitschrift fur Gesundheitswissenschaften $=$ Journal of public health, 2020, pp. 1-9.

[31] Parush, A., S. Ahuvia, and I. Erev, "Degradation in Spatial Knowledge Acquisition When Using Automatic Navigation Systems", in Spatial information theory: 8th international conference, COSIT 2007, Melbourne, Australia, September 19 - 23, 2007 ; proceedings, S. Winter, M. Duckham, L. Kulik, and B. Kuipers, Editors. 2007. Springer: Berlin, Heidelberg.

[32] Ramezani, R., W. Zhang, Z. Xie, J. Shen, D. Elashoff, P. Roberts, A. Stanton, M. Eslami, N. Wenger, M. Sarrafzadeh, and A. Naeim, "A Combination of Indoor Localization and Wearable Sensor-Based Physical Activity Recognition to Assess Older Patients Undergoing Subacute Rehabilitation: Baseline Study Results", JMIR mHealth and uHealth, 7(7), 2019, e14090.

[33] Boytchev, H., Wehrmeyer, S., "Schlampige Hygiene im Krankenhaus fuehrt zu mehr Toten als im Strassenverkehr", https://correctiv.org/aktuelles/gesundheit/gefaehrlichekeime/2017/01/11/schlampige-hygiene-im-krankenhausfuehrt-zu-mehr-toten-als-im-strassenverkehr, accessed 5-14-2020.

[34] Schönberger, M. and A. Čirjevskis, "Successful IT/IS Projects in Healthcare: Evaluation of Critical Success Factors", Journal of e-health Management, 2017, 2017, pp. 1-18.

[35] Sheppard, B.H., J. Hartwick, and P.R. Warshaw, "The Theory of Reasoned Action: A Meta-Analysis of Past Research with Recommendations for Modifications and Future Research", Journal of Consumer Research, 15(3), 1988, pp. 325-343.

[36] Infsoft $\mathrm{GmbH}$, https://www.infsoft.com/de/branchen/gesundheitpharma, accessed 5-19-2020.

[37] Sonitor Technologies AS, https://www.sonitor.com/.

[38] Zafari, F., A. Gkelias, and K.K. Leung, "A Survey of Indoor Localization Systems and Technologies", IEEE Communications Surveys \& Tutorials, 21(3), 2019, pp. 2568-2599.

[39] Zimmerman, T. and A. Zimmermann, Gartner Magic Quadrant for Indoor Location Services, Global, Gartner Research, 2019. 


\section{Appendix}

\section{A-1: Questionnaire}

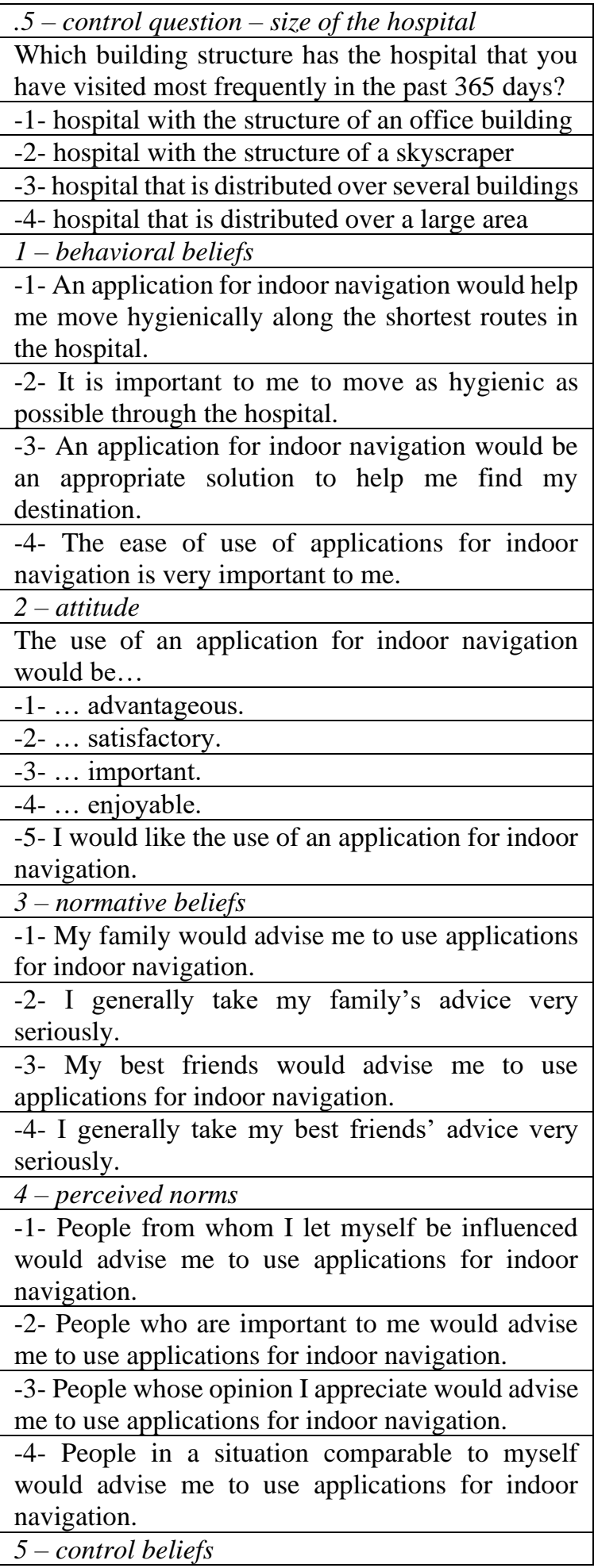

-1- I would use this application for indoor navigation because it would be easily accessible to me.

-2- The easy accessibility to applications for indoor navigation is very important to me.

-3- I would use this application for indoor navigation as far as I get the application explained accordingly.

-4- The explanation of the use of an application for indoor navigation is very important to me.

6 - perceived behavioral control

-1- It is under my control to use applications for indoor navigation.

-2- It is mainly up to me to use applications for indoor navigation.

-3- I am convinced that I can use applications for indoor navigation.

-4- If I really want to, I can use applications for indoor navigation.

7 -intention

-1- I would definitely use such an application for indoor navigation during my next visit to a hospital if it would be available. Mean Value: 5.35, Standard Deviation: 1.60

-2- I intend to use such an application for indoor navigation during my next visit to a hospital if it would be available. Mean Value: 5.39, Standard Deviation: 1.57

-3- I plan to use such an application for indoor navigation during my next visit to a hospital if it would be available. Mean Value: 5.27, Standard Deviation: 1.61

8 -spatial abilities

-1- I am good in navigating myself through buildings.

-2- I always find the shortest way through buildings while I am navigating myself.

-3- I do not need assistance while navigating myself through buildings.

9 - personal innovativeness

-1- When I hear about new information technology, I look forward to experimenting with it.

-2- I am usually the first of my friends to try new information technology.

-3- Basically, I am reluctant to try out new information technologies.

-4- I like to experiment with new information technologies.

\section{A-2: Loadings of reflective variables}

\begin{tabular}{|c|c|c|}
\hline $\begin{array}{c}\text { Cons- } \\
\text { truct }\end{array}$ & Item & $\begin{array}{c}\text { Loa- } \\
\text { dings }\end{array}$ \\
\hline
\end{tabular}




\begin{tabular}{|c|c|c|}
\hline & A-1/2-Att / -1- & 0.908 \\
\hline \multirow{4}{*}{ 荤 } & A-1 / 2-Att / -2- & 0.852 \\
\hline & A-1/2-Att / -3- & 0.833 \\
\hline & A-1/2-Att / -4- & 0.86 \\
\hline & A-1/2-Att / -5- & 0.924 \\
\hline \multirow{4}{*}{ Z } & A-1/4-PN/-1- & 0.918 \\
\hline & A-1/4-PN/-2- & 0.948 \\
\hline & A-1/4-PN/ -3- & 0.948 \\
\hline & A-1 / 4-PN/ -4- & 0.863 \\
\hline \multirow{4}{*}{ 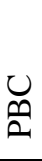 } & $\mathrm{A}-1 / 6-P B C /-1-$ & 0.761 \\
\hline & A-1 / 6-PBC/-2- & 0.825 \\
\hline & $\mathrm{A}-1 / 6-P B C /-3-$ & 0.849 \\
\hline & A-1 / 6-PBC/ -4- & 0.853 \\
\hline \multirow[b]{3}{*}{ 一 } & A-1/7-I/-1- & 0.954 \\
\hline & $\mathrm{A}-1 / 7-I /-2-$ & 0.975 \\
\hline & A-1 / 7-I/ -3- & 0.973 \\
\hline
\end{tabular}

\section{A-3: VIF values}

\begin{tabular}{|l|l|}
\hline Item & VIF \\
\hline $\mathrm{A}-1 / 1-B B /-1-\mathrm{x} A-1 / 1-B B /-2-(\mathrm{BB} 1)$ & 2.1 \\
\hline $\mathrm{A}-1 / 1-B B /-3-\mathrm{x} A-1 / 1-B B /-4-(\mathrm{BB} 2)$ & 2.1 \\
\hline $\mathrm{A}-1 / 3-N B /-1-\mathrm{x}$ A-1 $/ 3-N B /-2-(\mathrm{NB} 1)$ & 1.807 \\
\hline $\mathrm{A}-1 / 3-N B /-3-\mathrm{x} A-1 / 3-N B /-4-(\mathrm{NB} 2)$ & 1.807 \\
\hline $\mathrm{A}-1 / 5-C B /-1-\mathrm{x}$ A-1 $/ 5-C B /-2-(\mathrm{CB} 1)$ & 1.285 \\
\hline $\mathrm{A}-1 / 5-C B /-3-\mathrm{x}$ A-1 $/ 5-C B /-4-(\mathrm{CB} 2)$ & 1.285 \\
\hline
\end{tabular}

\section{A-4: Loadings and weights of formative} variables

\begin{tabular}{|l|l|l|l|}
\hline Construct & Item & Loadings & Weights \\
\hline \multirow{2}{*}{$\begin{array}{l}\text { behavioral } \\
\text { beliefs }\end{array}$} & (BB1) & 0.938 & 0.574 \\
\cline { 2 - 4 } & (BB2) & 0.918 & 0.503 \\
\hline \multirow{2}{*}{$\begin{array}{l}\text { normative } \\
\text { beliefs }\end{array}$} & (NB1) & 0.884 & 0.463 \\
\cline { 2 - 4 } & (NB2) & 0.939 & 0.629 \\
\hline $\begin{array}{l}\text { control } \\
\text { beliefs }\end{array}$ & (CB1) & 0.957 & 1.111 \\
\cline { 2 - 4 } & (CB2) & 0.196 & -0.327 \\
\hline
\end{tabular}

A-5: Descriptive statistics of the overall sample and correlations among variables $(\mathrm{N}=323)$

\begin{tabular}{|c|c|c|c|c|c|c|c|c|c|c|}
\hline & $\mathrm{M}$ & SD & BB & NB & CB & Att & PN & PBC & SA & I \\
\hline BB & 33.04 & 11.12 & 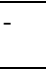 & $.51^{* * *}$ & $.67^{* * *}$ & $.77^{* * *}$ & $.53^{* * *}$ & $.38^{* * * *}$ & $-{ }^{-21^{* * *}}$ & $.70^{*}$ \\
\hline NB & 23.75 & 10.44 & & - & $.52^{* * *}$ & $.56^{* * *}$ & $.79^{* * * *}$ & $.21^{* * *}$ & .03 & $.49^{*}$ \\
\hline CB & 30.24 & 11.27 & & & - & $.67^{* * *}$ & $.58^{* * * *}$ & $.28^{* * *}$ & $-.15^{* *}$ & \begin{tabular}{|l}
$.71^{*}$ \\
$*_{*}^{*}$
\end{tabular} \\
\hline Att & 5.55 & 1.13 & & & & - & $.59^{* * * *}$ & $.36^{* * *}$ & $-.16^{* *}$ & $.74^{*}$ \\
\hline PN & 4.64 & 1.30 & & & & & - & $.15^{* *}$ & -.09 & $.59^{*}$ \\
\hline
\end{tabular}

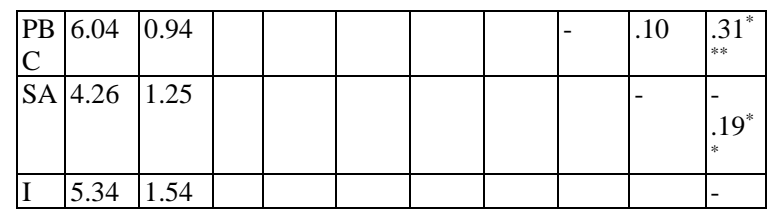

\section{A-6: Composite reliability and AVE}

\begin{tabular}{|l|l|l|}
\hline & $\begin{array}{l}\text { Average } \\
\text { Variance } \\
\text { Reliability }\end{array}$ \\
$\begin{array}{l}\text { Extracted } \\
\text { (AVE) }\end{array}$ \\
\hline attitude & 0.943 & 0.767 \\
\hline perceived norms & 0.956 & 0.846 \\
\hline spatial abilites & 0.906 & 0.764 \\
\hline intention & 0.978 & 0.936 \\
\hline personal innovativen. & 0.908 & 0.714 \\
\hline perc. behav. control & 0.893 & 0.677 \\
\hline
\end{tabular}

\section{A-7: HTMT values}

\begin{tabular}{|c|c|c|c|c|c|c|c|c|c|c|}
\hline & $\begin{array}{c}\mathrm{A} \\
\mathrm{ge}\end{array}$ & 2 & $\begin{array}{c}\mathrm{At} \\
\mathrm{t}\end{array}$ & $\begin{array}{c}\mathrm{P} \\
\mathrm{N}\end{array}$ & $\begin{array}{c}\mathrm{S} \\
\mathrm{A}\end{array}$ & 6 & $\mathrm{I}$ & $\mathrm{PI}$ & $\begin{array}{c}\mathrm{B} \\
\mathrm{C}\end{array}$ \\
\hline 1 & & & & & & & & & & 1 \\
\hline 2 & .0 & & & & & & & & & 2 \\
\hline $\mathrm{At}$ & .0 & .0 & & & & & & & & $\mathrm{~A}$ \\
$\mathrm{t}$ & 92 & 31 & & & & & & & & $\mathrm{tt}$ \\
\hline $\mathrm{P}$ & .0 & .0 & .6 & & & & & & & $\mathrm{P}$ \\
$\mathrm{N}$ & 28 & 38 & 33 & & & & & & & $\mathrm{~N}$ \\
\hline $\mathrm{S}$ & .0 & .0 & .1 & .1 & & & & & & $\mathrm{~S}$ \\
$\mathrm{~A}$ & 86 & 09 & 88 & 02 & & & & & & $\mathrm{~A}$ \\
\hline 6 & .0 & .0 & .1 & .1 & .1 & & & & & 6 \\
\hline 7 & .0 & .1 & .0 & .0 & .0 & .1 & & & & 7 \\
\hline $\mathrm{I}$ & .0 & .0 & .7 & .6 & .2 & .0 & .0 & & & $\mathrm{I}$ \\
\hline $\mathrm{PI}$ & .1 & .0 & .3 & .3 & .7 & .1 & .0 & .3 & & $\mathrm{P}$ \\
\hline $\mathrm{P}$ & & & & & & & & & & \\
$\mathrm{B}$ & .0 & .0 & .4 & .1 & .0 & .0 & .0 & .3 & .3 & $\mathrm{~B}$ \\
$\mathrm{C}$ & 43 & 30 & 14 & 73 & 80 & 28 & 28 & 45 & 32 & $\mathrm{C}$ \\
\hline
\end{tabular}

$1=$ age; $2=$ number of visits: $6=$ gender: $7=$ hospital size

\section{A-8: Stone-Geisser-values}

\begin{tabular}{|l|l|}
\hline & $\mathrm{Q}^{2}(=1-\mathrm{SSE} / \mathrm{SSO})$ \\
\hline attitude & 0.457 \\
\hline perceived norms & 0.527 \\
\hline capabilities & 0.012 \\
\hline intention & 0.560 \\
\hline perc. behav. control & 0.147 \\
\hline
\end{tabular}

